Aim of the study: The cancer incidence in Wielkopolska in 2008 was one of the highest in the country and was higher than in Poland by $21 \%$ in men and by $14 \%$ in women. We can quantify the future burden of cancer from two different perspectives: the number of new cancer cases due to population change and new cases due to risk change. Making predictions of number of new cancer cases in Wielkopolska in 2018.

Material and methods: These projections of number of cancer cases, age specific rates and age-standardized rates for 2018 (all cancers and the most frequent cancers for men and women) has been based on the historical trends of cancer incidence in Wielkopolska in 1999-2008 and demographical prognosis of Central Statistical Office using the method of Hakulinen and Dyba. Results: There will be over 8000 new cancer cases in men in Wielkopolska in 2018 and over 7000 in women. Compare to the period 2004-2008 the number of cancer cases will increase by $45 \%$ for men and by nearly $30 \%$ for women. About $2 / 3$ of the increase in Wielkopolska is predicted to be connected with demography change, $1 / 3$ with risk change.

Conclusions: The predicted increase of number of cancer cases in Wielkopolska in 2018 will be the result of: changes in the population (bigger impact of the older age groups), an influence of the risk factors (mainly smoking) and a participation in the screening programs.

Key words: cancer, incidence, predictions, demography, risk.

\section{Predictions of cancer incidence in Wielkopolska in 2018}

\author{
Dariusz Godlewski ${ }^{1}$, Piotr Wojtyśs ${ }^{1}$, Andrzej Antczak ${ }^{2}$
}

${ }^{1}$ Center of Cancer Prevention and Epidemiology OPEN, Poznań, Poland 2Katedra i Klinika Urologii i Onkologii Urologicznej, Poznan University of Medical Sciences, Poland

\section{Introduction}

In 2008, 6649 new cancer cases among men and 6294 cases among women were registered in Wielkopolska [1]. In the whole country, 65477 new cancer cases in men and 65586 cases in women were registered [2]. Cancer incidence among men in Wielkopolska in 2008 (298.9 per 100 000) was higher than the incidence in the whole of Poland by $21 \%$, SRR (standardized rate ratio) $=1.21$, $95 \% \mathrm{Cl}=1.18-1.25$ (incidence in Poland 246.1 per 100 000). Incidence among women in Wielkopolska (224.6 per 100 000) was higher than in Poland by $14 \%$, $\mathrm{SRR}=1.14,95 \% \mathrm{Cl}=1.11-1.17$ (incidence in Poland 197.3 per 100 000) [2].

The most frequent cancer among males in Wielkopolska was lung cancer (19.4\%), followed by prostate cancer (15.0\%), colorectal cancer (10.9\%), bladder cancer (6.5\%), stomach cancer (4.7\%) and kidney cancer (4.1\%) (Fig. 1). Among females the most frequent cancer was breast (22.1\%), then colorectal cancer (9.6\%), lung cancer (7.7\%), corpus uteri cancer (6.5\%), cervical cancer (4.6\%) and ovarian cancer (4.6\%) (Fig. 2).

An increase of incidence for colorectal cancer, prostate cancer (very rapid acceleration after 1995), bladder cancer and kidney cancer was observed between 1985 and 2008 among men in Wielkopolska. After the initial increase for lung cancer the rates changed in 1998 and the incidence slowly began to decrease. A steady decrease of incidence was observed in the years 1985-2008 for stomach cancer (Fig. 3). Among women we observed an increase of incidence for breast cancer, lung cancer and endometrial cancer. In the years 19851999 an increasing trend for colorectal cancer occurred and after this period the rates remained at a stable level. A constant level of incidence in the years 1998-2008 was observed for ovarian cancer. A decreasing tendency for the 1985-2008 period was characteristic for cervical cancer (Fig. 4).

The predicted number of cancer cases in the future will be the result of changes in the age composition of the population, size of the population and historical trends of cancer incidence. We can quantify the future burden of cancer from two perspectives [3]. Firstly, age-standardized rates describe the occurrence of cancer on a per capita basis, taking account of changes in age composition and size of the population [4]. Secondly, from the point of view of cancer care and cancer services provision, the burden of cancer is more usefully measured as the total number of persons with cancer who require diagnostic, therapeutic, supportive or palliative services [5]. Predictions could be useful in planning the allocation of the sources as well as in evaluation of the disease control (primary prevention, screening programmes).

The biggest determinant of the level of cancers in the future is the process of an ageing population, as cancer is a disease more common in older people. While age-standardized rates may decrease for several cancers in Wielkopolska, the absolute number of cancer cases will increase. Most cancers (69\% in men and 58\% in women) in Wielkopolska are diagnosed in the population over 60 , so any change in the size of this population is an important factor for the future cancer incidence. The predicted changes in the size 


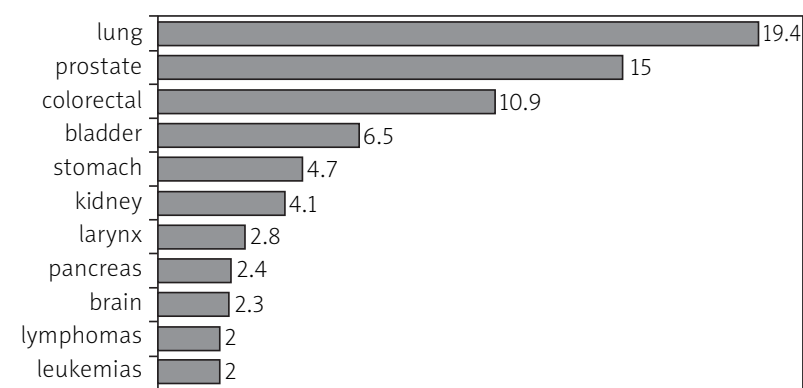

Fig. 1. The structure of incidence in Wielkopolska, men, year 2008. Number of new cancer cases among males: 6649

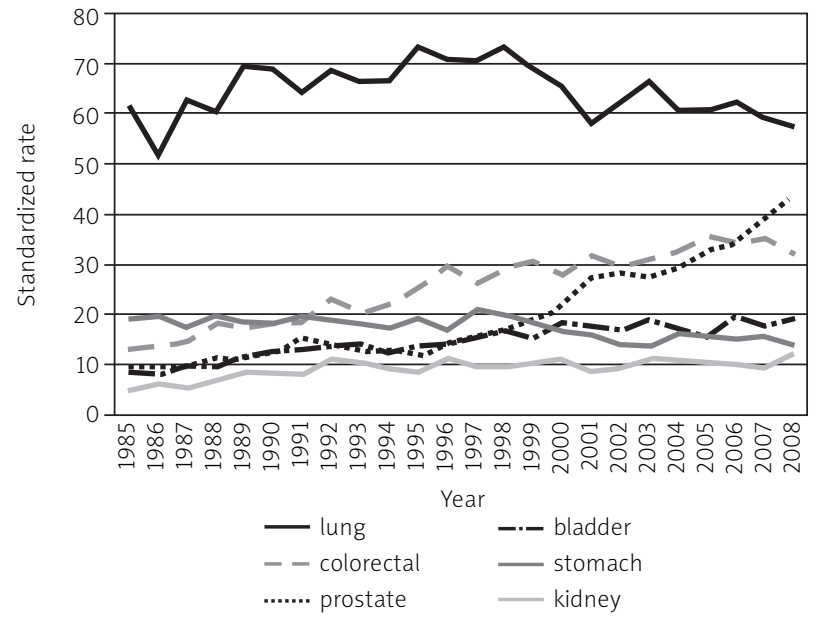

Fig. 3. Incidence trends for the most frequent cancers among men in Wielkopolska. Standardized rate per 100000

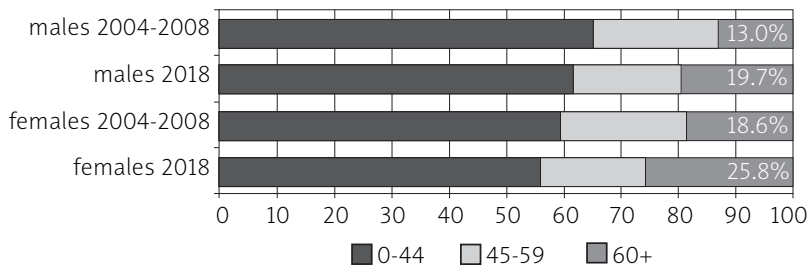

Fig. 5. Demographic prognosis for Wielkopolska

and composition of the population (the increase of the population over 60) will be connected with the increasing number of new registered cancer cases. Figure 5 shows the composition of Wielkopolska male and female population in the years 2004-2008 and the predicted size and structure of the population in 2018. The male population over 60 will increase from 212920 (average mean for the 2004-2008 period) to 330895 in 2018. The percentage of this population will increase from $13.0 \%$ to $19.7 \%$. The number of females over 60 will change from 322690 to 460827 and the percentage from $18.6 \%$ to $25.8 \%$.

\section{Material and methods}

The cancer incidence rates in Wielkopolska in the years 1999-2008 were calculated using the Regional Cancer Registry data (new cancer cases) and the population data from

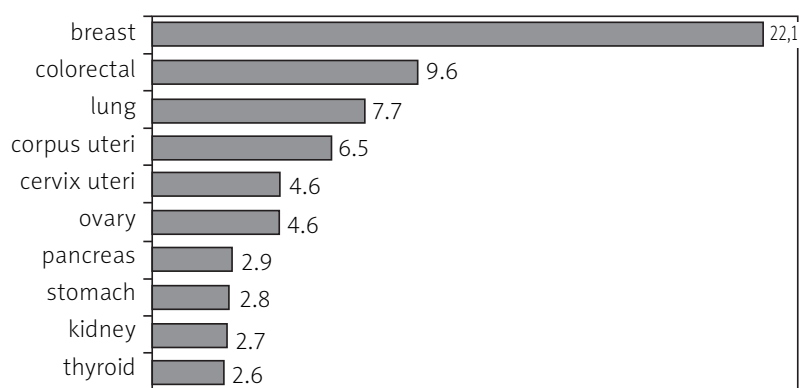

Fig. 2. The structure of incidence in Wielkopolska, women, year 2008. Number of new cancer cases among females: 6294

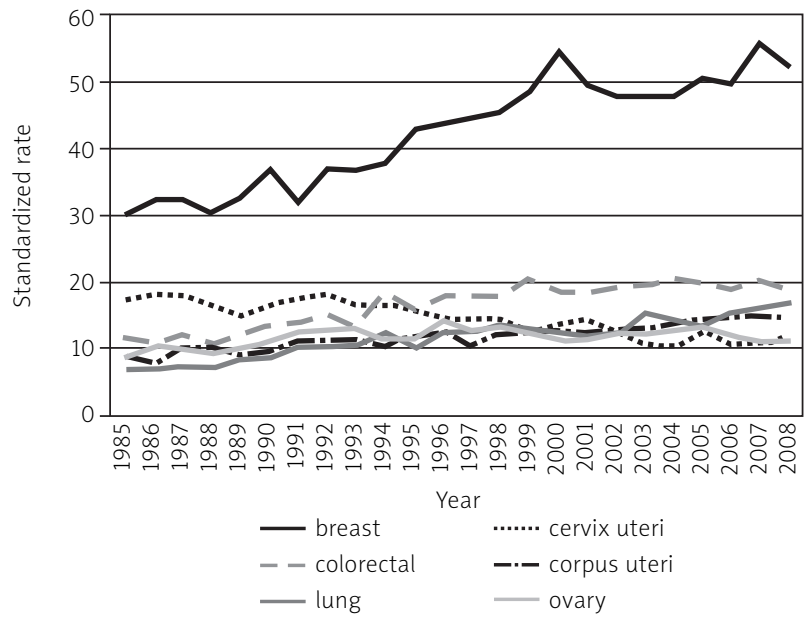

Fig. 4. Incidence trends for the most frequent cancers among women in Wielkopolska. Standardized rate per 100000

the Statistical Office. The World Standard Population was used for calculation of age-standardized rates. It is worth underlining that the Wielkopolska Regional Cancer Registry is the one with the highest data completeness in Poland, which improves the accuracy of the prognosis [2].

In Poland the $10^{\text {th }}$ Revision of the International Classification of Diseases (1994) is currently binding. The predicted number of cancer cases, age-specific rates and age-standardized rates for the most frequent cancer sites among men and women in 2018 were calculated on the basis of the historical incidence trends for Wielkopolska in the years 1999 2008 and the demographic prognosis created by the Central Statistical Office [6] using the method of Dyba and Hakulinen. The following underlying theoretical assumptions apply to these analyses:

1. Future incidence trends can be modelled by extrapolating a historic trend.

2. The lengths of the data time series permit the estimation of models that take account of age-sex group specific trends.

3. The number of cancer cases in each age-sex-time period stratum are Poisson distributed.

4. Where historic trends in standardized incidence are decreasing, a log-linear model is appropriate to estimate the average rate, whereas a linear model is used for increasing or constant trends to avoid explosive growth. 
Poisson linear and log-linear models were fitted to agespecific cancer incidence rates for the age groups 0-44, 45-49, 50-54, 55-59, 60-64, 65-69, 70-74, 75-79, 80-84, 85 and over. Due to the small number of cancer cases in the youngest age groups, the groups have been aggregated into one: 0-44. Estimates of the parameters for each of the models were calculated using the STATA 11.0 statistical package for Windows [7-11].

The predicted values for 2018 in Wielkopolska were compared to the years 2004-2008 (2004-2008 is used as a baseline, as a five-year average gives the most stable estimate of current numbers). The predicted values for Poland were compared to the year 2006. The percentage change in number of cases from 2004-2008 to 2018 was divided into one part due to increased risk of being diagnosed with cancer, and another due to changes in the population size and age distribution [12].

\section{Results}

Considered overall, the numbers of all cancers combined (excluding non-melanoma skin cancer) are predicted to increase for Poland and Wielkopolska for both sexes. A 45\% increase for the male population and $28.8 \%$ for females is predicted in Wielkopolska. The forecast for Poland is a 19.2\% increase for males and $24.3 \%$ for females. Tables 1 and 2 break down the increase into the contribution from change in pop- ulation and change in risk. The effect of demography is stronger than the effect of risk. About $2 / 3$ of the increase in Wielkopolska is predicted to be connected with demography change, $1 / 3$ with risk change. The forecasted effect of demography is slightly higher for Wielkopolska than for Poland. More cancers are diagnosed after the age of 60 for males and after the age of 50 for females in Wielkopolska compared to the whole country. For the male population in Poland the whole increase of number of cancers is due to the change in population. A decrease of risk will be observed for males in Poland. In Wielkopolska the increase in numbers of cancer cases will be the result of both change in population and change in risk. A notable difference in risk influence between Wielkopolska and Poland in males could be largely explained by the trends for lung cancer and prostate cancer. The increase in the number of cancer cases in females is predicted to be due to both the change in population and change in risk.

Table 3 shows the forecasted change in number of cancer cases in males in Wielkopolska and breaks down the change in incidence into the contribution from change in population and change in risk. For most cancers the effect of demography is between $25 \%$ and $35 \%$. The only cancer for which there is a decreasing tendency in number of cases connected with change in population is testicular cancer. The most notable increase in number of cancer cases due to risk will be

Table 1. Mean annual number of cases as observed in 2004-2008 in Wielkopolska, number of cases in Poland in 2006 and predicted for both population for 2018 by site, males. Corresponding percentage change in incidence, decomposed into changing risk and demographic components

\begin{tabular}{|c|c|c|c|c|c|c|c|c|}
\hline \multirow[t]{2}{*}{ ICD-10 } & \multirow[t]{2}{*}{ Site } & \multicolumn{3}{|c|}{ Number of cancer cases } & \multirow[t]{2}{*}{$\begin{array}{l}\text { Change } \\
\text { overall }\end{array}$} & \multirow[t]{2}{*}{$\begin{array}{c}\text { Change } \\
\text { overall (\%) }\end{array}$} & \multicolumn{2}{|c|}{$\begin{array}{l}\text { Change due } \\
\text { to change in: }\end{array}$} \\
\hline & & $\begin{array}{c}2004-2008 \\
(2006)\end{array}$ & 2018 & $95 \% \mathrm{Cl}$ & & & population (\%) & risk \% \\
\hline $\begin{array}{l}\text { C00-C97, } \\
\text { D00-D09 } \\
\text { excluding C44 }\end{array}$ & $\begin{array}{l}\text { ALL SITES } \\
\text { EXCLUDING NMSC* } \\
\text { WIELKOPOLSKA }\end{array}$ & 5637 & 8171 & $7778-8564$ & 2534 & 45.0 & 29.6 & 15.4 \\
\hline $\begin{array}{l}\text { C00-C97, } \\
\text { D00-D09 }\end{array}$ & $\begin{array}{l}\text { ALL SITES } \\
\text { excluding C } 44 \\
\text { EXCLUDING NMSC* } \\
\text { POLAND }\end{array}$ & 60168 & 71712 & $70069-73355$ & 11544 & 19.2 & 24.2 & -5.0 \\
\hline
\end{tabular}

${ }^{*}$ NMSC - non-melanoma skin cancer

Table 2. Mean annual number of cases as observed in 2004-2008 in Wielkopolska, number of cases in Poland in 2006 and predicted for both population for 2018 by site, females. Corresponding percentage change in incidence, decomposed into changing risk and demographic components

\begin{tabular}{|c|c|c|c|c|c|c|c|c|}
\hline \multirow[t]{2}{*}{ ICD-10 } & \multirow[t]{2}{*}{ Site } & \multicolumn{3}{|c|}{ Number of cancer cases } & \multirow[t]{2}{*}{$\begin{array}{l}\text { Change } \\
\text { overall }\end{array}$} & \multirow[t]{2}{*}{$\begin{array}{c}\text { Change } \\
\text { overall (\%) }\end{array}$} & \multicolumn{2}{|c|}{$\begin{array}{l}\text { Change due } \\
\text { to change in: }\end{array}$} \\
\hline & & $2004-2008$ & 2018 & $95 \% \mathrm{Cl}$ & & & population (\%) & risk \% \\
\hline $\begin{array}{l}\text { C00-C97, } \\
\text { D00-D09 } \\
\text { excluding C } 44\end{array}$ & $\begin{array}{l}\text { ALL SITES } \\
\text { EXCLUDING NMSC* } \\
\text { WIELKOPOLSKA }\end{array}$ & 5485 & 7064 & $6702-7426$ & 1579 & 28.8 & 19.5 & 9.3 \\
\hline $\begin{array}{l}\text { C00-C97, } \\
\text { D00-D09 } \\
\text { excluding C } 44\end{array}$ & $\begin{array}{l}\text { ALL SITES } \\
\text { EXCLUDING NMSC* } \\
\text { POLAND }\end{array}$ & 57621 & 71624 & 69 958-73290 & 14003 & 24.3 & 15.6 & 8.7 \\
\hline
\end{tabular}

*NMSC - non-melanoma skin cancer 
Table 3. Mean annual number of cases as observed in 2004-2008 in Wielkopolska and predicted for 2018 by site, males. Corresponding percentage change in incidence, decomposed into changing risk and demographic components

\begin{tabular}{|c|c|c|c|c|c|c|c|c|}
\hline \multirow[t]{2}{*}{ ICD-10 } & \multirow[t]{2}{*}{ Site } & \multicolumn{3}{|c|}{ Number of cancer cases } & \multirow[t]{2}{*}{$\begin{array}{l}\text { Change } \\
\text { overall }\end{array}$} & \multirow[t]{2}{*}{$\begin{array}{c}\text { Change } \\
\text { overall (\%) }\end{array}$} & \multicolumn{2}{|c|}{$\begin{array}{l}\text { Change due } \\
\text { to change in: }\end{array}$} \\
\hline & & $2004-2008$ & 2018 & $95 \% \mathrm{Cl}$ & & & population (\%) & risk \% \\
\hline $\mathrm{COO}-\mathrm{CO} 6$ & ORAL CAVITY & 110 & 82 & $52-113$ & -28 & -25.4 & 21.8 & -47.2 \\
\hline C15 & OESOPHAGUS & 95 & 122 & $75-169$ & 27 & 28.4 & 27.4 & 1.0 \\
\hline C16 & STOMACH & 326 & 330 & $261-400$ & 4 & 1.2 & 33.4 & -32.2 \\
\hline C18-C21 & COLORECTAL & 733 & 1160 & $1025-1294$ & 427 & 58.2 & 32.6 & 25.6 \\
\hline $\mathrm{C} 25$ & PANCREAS & 150 & 159 & $111-208$ & 9 & 6.0 & 29.3 & -23.3 \\
\hline C33-C34 & LUNG & 1287 & 1507 & $1347-1668$ & 220 & 17.1 & 31.5 & -14.4 \\
\hline C32 & LARYNX & 184 & 164 & $118-210$ & -20 & -10.9 & 25.0 & -35.9 \\
\hline C43 & MELANOMA & 99 & 170 & $122-219$ & 71 & 71.7 & 23.2 & 48.5 \\
\hline C61 & PROSTATE & 783 & 1944 & 1796-2092 & 1161 & 148.2 & 37.9 & 110.3 \\
\hline C62 & TESTIS & 99 & 105 & $67-143$ & 6 & 6.1 & -4.0 & 10.1 \\
\hline C64-C66, C68 & KIDNEY & 225 & 326 & $255-397$ & 101 & 44.9 & 26.7 & 18.2 \\
\hline $\mathrm{C} 67$ & BLADDER & 390 & 591 & $493-689$ & 201 & 51.5 & 31.3 & 20.2 \\
\hline C71-C72 & BRAIN & 123 & 155 & $106-205$ & 32 & 26.0 & 17.1 & 8.9 \\
\hline C82-C85 & LYMPHOMAS & 128 & 184 & $131-236$ & 56 & 43.7 & 25.0 & 18.7 \\
\hline C91-C95 & LEUKAEMIAS & 133 & 162 & $103-222$ & 29 & 21.8 & 21.0 & 0.8 \\
\hline
\end{tabular}

observed for prostate cancer. An increasing tendency connected with risk will be characteristic also for colorectal cancer, melanoma skin cancer, kidney cancer, bladder cancer and lymphomas. For several cancers a decrease in the number of cases connected with risk influence is predicted (oral cavity cancer, stomach cancer, pancreatic cancer, lung cancer, laryngeal cancer). For lung cancer, despite the decreasing tendency connected with risk there is still an increasing trend in change overall because of the strong influence of demography. For pancreatic cancer and stomach cancer the increasing tendency connected with demography is compensated by the decreasing tendency connected with risk.

Taking into consideration both demographic change and change in risk, the estimated numbers of new cancers in females in Wielkopolska are shown in Table 4. The influence of change in population for most cancers will be slightly lower than in males, $15-25 \%$. The highest increase in number of cancer cases due to demography is predicted for pancreatic cancer (27.2\%), bladder cancer (26.4\%) and gallbladder cancer (25.8\%). High diversity is observed for the change in the number of cancer cases connected with risk influence. A substantial increasing tendency is predicted for bladder cancer (56.6\%), lung cancer (44.2\%), endometrial cancer $(32.3 \%)$ and lymphomas (31.8\%). The analysis forecasts a decrease in the number of cancer cases due to risk of stomach cancer, gallbladder cancer, ovarian cancer and cervical cancer. A notable difference in the predicted change in number of cases between the male and female population is seen for colorectal cancer. In females the whole increase (24.6\%) is predicted to be connected with demography. In males the predicted increase is higher (58.2\%) and will be the result of a change in demography as well as a change in risk.

\section{Discussion}

Future changes in the number of cancers occurring in the population are only predictable if they are linear extensions of past trends; otherwise, future period effects are not predictable from past rates. This is a major source of uncertainty in cancer forecasts and is the main reason why many predictions turn out to be too low or too high. The analysis makes no assumption about changes in exposure to risk factors, but relies entirely on the extrapolation of the recorded rates in the past. These predictions also assume that current trends will remain unchanged in the future. With respect to random error control the continuation of a trend is a successful way of making cancer incidence predictions up to 10 years into the future. For a longer period, the random error becomes too large $[3,10,13]$.

The model of cancer prognosis for both male and female lung cancer could be improved upon by the inclusion of information on smoking, as about $90 \%$ of lung cancers are directly attributed to tobacco $[14,15]$.

It should be emphasized that the predicted numbers of cases are uncertain and the prediction holds true as long as there are no qualitative or major quantitative changes in any of the underlying factors (smoking habits, screening programmes) [11]. The trends may also be affected by changes in the definitions or diagnostic criteria. A new factor can affect the whole population or only a part of it. The imple- 
Table 4. Mean annual number of cases as observed in 2004-2008 in Wielkopolska and predicted for 2018 by site, females. Corresponding percentage change in incidence, decomposed into changing risk and demographic components

\begin{tabular}{|c|c|c|c|c|c|c|c|c|}
\hline \multirow[t]{2}{*}{ ICD-10 } & \multirow[t]{2}{*}{ Site } & \multicolumn{3}{|c|}{ Number of cancer cases } & \multirow[t]{2}{*}{$\begin{array}{l}\text { Change } \\
\text { overall }\end{array}$} & \multirow[t]{2}{*}{$\begin{array}{c}\text { Change } \\
\text { overall (\%) }\end{array}$} & \multicolumn{2}{|c|}{$\begin{array}{l}\text { Change due } \\
\text { to change in: }\end{array}$} \\
\hline & & $2004-2008$ & 2018 & $95 \% \mathrm{Cl}$ & & & population (\%) & risk \% \\
\hline C16 & STOMACH & 163 & 122 & $85-159$ & -41 & -25.2 & 23.9 & -49.1 \\
\hline C18-C21 & COLORECTAL & 604 & 753 & $637-868$ & 149 & 24.6 & 24.8 & -0.2 \\
\hline C23-C24 & GALLBLADDER & 116 & 86 & $55-117$ & -30 & -25.9 & 25.8 & -51.7 \\
\hline $\mathrm{C} 25$ & PANCREAS & 151 & 194 & $138-250$ & 43 & 28.5 & 27.2 & 1.3 \\
\hline C33-C34 & LUNG & 425 & 706 & $611-801$ & 281 & 66.1 & 21.9 & 44.2 \\
\hline C43 & MELANOMA & 107 & 131 & $83-178$ & 24 & 22.4 & 18.7 & 3.7 \\
\hline C50 & BREAST & 1321 & 1711 & 1508-1914 & 390 & 29.5 & 17.7 & 11.8 \\
\hline C54 & CORPUS UTERI & 390 & 600 & $508-692$ & 210 & 53.8 & 21.5 & 32.3 \\
\hline C56 & OVARY & 309 & 336 & $258-413$ & 27 & 8.8 & 15.9 & -7.1 \\
\hline C53 & CERVIX UTERI & 272 & 243 & $187-299$ & -29 & -10.7 & 13.6 & -24.3 \\
\hline C64-C66, C68 & KIDNEY & 145 & 212 & $155-268$ & 67 & 46.2 & 23.4 & 22.8 \\
\hline C67 & BLADDER & 106 & 194 & $145-244$ & 88 & 83.0 & 26.4 & 56.6 \\
\hline C71-C72 & BRAIN & 116 & 148 & 99-196 & 32 & 27.6 & 14.7 & 12.9 \\
\hline $\mathrm{C} 73$ & THYROID & 149 & 181 & $128-234$ & 32 & 21.5 & 9.4 & 12.1 \\
\hline C82-C85 & LYMPHOMAS & 113 & 171 & $122-219$ & 58 & 51.3 & 19.5 & 31.8 \\
\hline C91-C95 & LEUKAEMIAS & 109 & 138 & $91-185$ & 29 & 26.6 & 19.3 & 7.3 \\
\hline
\end{tabular}

mentation of the breast cancer screening programme affects only women aged 50-69. When predictions for breast cancer in Wielkopolska were restricted only to females aged $50-69$, an increase of $49.5 \%$ was achieved $29.5 \%$ for the whole female population). The contribution of increase due to risk rises from $11.8 \%$ for all females to $27.9 \%$ for the age group 50-69. An improvement in the screening participation rate will increase the number of new breast cancer cases due to early diagnosis of cases which in the absence of screening would be detected later or would not be detected at all (overdiagnosis cases). So it may appear that the predicted values are too low.

In the analysis for Nordic countries, the errors of predicted numbers compared with actual numbers observed subsequently were typically $10-20 \%$ on either side [16]. A similar analysis in Scotland showed that half of the predicted future numbers were incorrect by more than $10 \%$ and a fifth by more than 20\% [17].

The single most critical aspect of these predictions concerns the future number of prostate cancer cases. The standard set of assumptions would predict more than a double increase in the number of cases. A very sharp increase in incidence is predicted also for Poland in 2020 in the analysis made by Didkowska and co-authors [18]. We considered these prognoses rather unlikely so we decided to assume that the age-specific rates in 2004-2008 would remain constant, so that the future number of prostate cancer cases would increase only in consequence of demographic changes in the population. On the basis of this assumption the predicted number of cases in 2018 is 1080 (instead of 1944). That means an increase by $37.9 \%$. The real number of prostate cancer cases in the future will depend on the continuation of the present trend, a 10.6\% increase of age-standardized rate per year in 1995-2008. The future use of prostate-specific antigen (PSA) testing will be very important. The number of cancer cases among older men may increase if the use of PSA testing in asymptomatic men in this age group increases.

In a few countries with very high prostate cancer incidence (Sweden, Finland, the Netherlands) the rate has begun to fall in the last years [19].

The fact that the prediction does not come true may indicate success of a cancer prevention method. A prediction made by extrapolation shows how large the incidence would be if the trend in the incidence were not affected [10]. The major concern of primary prevention is the reduction of smoking. Success of this campaign will result in a lower than expected number of cancer cases connected with smoking (especially lung cancer). Participation in mass screening programmes aimed at early detection of precancerous lesions has decreased the incidence of cervical cancer so the predicted numbers of cancer cases would be too high. A breast cancer screening programme aimed at early detection of cancer leads to an increase of incidence above the expectations.

\section{References}

1. Dyzmann-Sroka A, Myślińska W, Olenderczyk W, et al. Cancer in the Greater Poland province in 2008. Poznań 2010.

2. Wojciechowska U, Didkowska J, Zatoński W. Cancer in Poland in 2008. Warszawa 2010 
3. Møller H, Fairley L, Coupland V, Okello C, Green M, Forman D, Møller B, Bray F. The future burden of cancer in England: incidence and numbers of new patients in 2020. Br J Cancer 2007; 96: 1484-8.

4. Parkin DM. The evolution of the population-based cancer registry. Nat Rev Cancer 2006; 6: 603-12.

5. Bray F, Møller B. Predicting the future burden of cancer. Nat Rev Cancer 2006; 6: 63-74.

6. http://demografia.stat.gov.pl/BazaDemografia/Prognoza.aspx. Accessed February 2011.

7. Dyba T, Hakulinen T. Comparison of different approaches to incidence prediction based on simple interpolation techniques. Stat Med 2000; 19: 1741-52.

8. Hakulinen T, Dyba T. Precision of incidence predictions based on Poisson distributed observations. Stat Med 1994; 13: 1513-23.

9. Dyba T, Hakulinen T, Päivärinta L. A simple non-linear model in incidence prediction. Stat Med 1997; 16: 2297-309.

10. Hakulinen T, Teppo L, Saxén E. Do the predictions for cancer incidence come true? Experience from Finland. Cancer 1986; 57: 2454-8.

11. Trends in Irish cancer incidence 1994-2002 with projections to 2020. National Cancer Registry, June 2006.

12. Møller B, Fekjaer H, Hakulinen T, Tryggvadóttir L, Storm HH, Talbäck M, Haldorsen T. Prediction of cancer incidence in the Nordic countries up to the year 2020. Eur J Cancer Prev 2002; 11 Suppl 1: S1-S96.

13. French D, Catney D, Gavin AT. Modelling predictions of cancer deaths in Northern Ireland. Ulster Med J 2006; 75: 120-5.

14. Cancer Research UK. Lifestyle and cancer risk in the UK population: Cancerstats report. Available from: http://info.cancerresearchuk.org/ cancerstats/causes/lifestyle/. Accessed March 2011.

15. Didkowska J, Wojciechowska U, Koskinen HL, Tavilla A, Dyba T, Hakulinen T. Future lung cancer incidence in Poland and Finland based on forecasts on hypothetical changes in smoking status. Acta Oncol 2011; 50: 81-7.

16. Møller B, Fekjaer H, Hakulinen T, Sigvaldason H, Storm HH, Talbäck M, Haldorsen T. Prediction of cancer incidence in the Nordic countries: empirical comparison of different approaches. Stat Med 2003; 22: 2751-66.

17. Scottish Executive Cancer in Scotland Sustaining Change 2004 Assessed March 2011.

18. Didkowska J, Wojciechowska U, Zatoński W. Prediction of cancer incidence and mortality in Poland up to the year 2025. Warszawa 2009.

19. Bray F, Lortet-Tieulent J, Ferlay J, Forman D, Auvinen A. Prostate cancer incidence and mortality trends in 37 European countries: an overview. Eur J Cancer 2010; 46: 3040-52.

\section{Address for correspondence}

\section{Dariusz Godlewsk}

Ośrodek Profilaktyki i Epidemiologii Nowotworów

ul. Kazimierza Wielkiego 24/26

61-863 Poznań

tel. +48 618518627

e-mail: godlewski.open@wp.pl

Submitted: $\quad 27.05 .201$

Accepted: $\quad 18.01 .2012$ 